\title{
Association between Leptospirosis-Related Knowledge and Practices of Male Pedicab Drivers in Manila
}

\author{
Patricia Abigail C. Lim, ${ }^{1}$ Ma. Bituin S. Reyes, ${ }^{1}$ Diana Jean V. Vasquez, ${ }^{1}$ \\ Raphael Jourdain L. Lim ${ }^{1}$ and Maylin C. Palatino ${ }^{1,2}$ \\ ${ }^{1}$ College of Public Health, University of the Philippines Manila \\ ${ }^{2}$ Department of Epidemiology and Biostatistics, College of Public Health, University of the Philippines Manila
}

\begin{abstract}
Objective. The study aimed to determine whether or not an association exists between leptospirosis-related knowledge and the practices of pedicab drivers in Manila.

Methods. An analytic, cross-sectional study was done among 174 male pedicab drivers. Face-to-face interviews were conducted using an interview schedule containing 12 questions covering knowledge of transmission and prevention, and 8 questions covering preventive occupation-related practices against leptospirosis. Logistic regression was employed to examine association while controlling for the confounding effects of other variables.
\end{abstract}

Results. Forty-nine percent were found to have good knowledge on the transmission and prevention of leptospirosis while $21 \%$ had satisfactory preventive and health-seeking practice. After controlling for the confounding effect of pedicab ownership, the odds of having unsatisfactory practices among those with low knowledge were found to be 13 times higher than those with good knowledge. Education was found to be an effect measure modifier.

Conclusion. The results suggest that a low level of education combined with poor leptospirosis-related knowledge has a magnified effect on practices. Increasing the knowledge of pedicab drivers especially those with a low level of education is necessary to improve their practices. Information dissemination on leptospirosis should be further intensified. Collaboration between health workers and organizations of pedicab drivers can be done to organize health information seminars.

Key Words: Leptospirosis, knowledge and practices, prevention and control

Corresponding author: Maylin C. Palatino, MSPH

Department of Epidemiology and Biostatistics

College of Public Health

University of the Philippines Manila

625 Pedro Gil Street, Ermita, Manila 1000 Philippines

Telephone: +6325260784

Email: mimipalatino@gmail.com

\section{Introduction}

Leptospirosis is a pervasive disease that affects both animals and humans. ${ }^{1}$ It is a potentially serious but treatable zoonotic disease, representing a worldwide public health hazard. It is transferred from the urine of infected animals either directly, through breaks in the skin or mucous membrane, or indirectly, via contaminated soil or water. ${ }^{2}$

A number of environmental risk factors are associated with leptospirosis. It is more common in tropical countries such as Thailand, Laos, Vietnam, and the Philippines since leptospires can survive longer in hot and humid environments. ${ }^{3,4,5}$ In addition, poor sanitation and waste disposal coupled with rainfall and flooding can increase the incidence of leptospirosis in poor urban areas., ${ }^{4,6}$ A surge of leptospirosis cases is usually observed in the wake of a typhoon or after heavy monsoon rains. ${ }^{7}$

In the Philippines, the trend of morbidity has steadily decreased over the past few years. ${ }^{8}$ From January to the first week of September 2013, 1,174 cases of leptospirosis were reported, a 79\% drop in the rate reported from the same time period in 2012. ${ }^{9}$ Despite this, the disease still poses a major threat to the safety of many people, particularly in urban areas that are prone to flooding. According to the National Epidemiology Center of the Department of Health, 7,687 cases of leptospirosis were reported in 2012. The highest number of cases was seen in the month of August $(2,789$ cases), accounting for $36 \%$ of the total number of cases for that year. This was due to the massive flooding in many areas of Luzon, including Metro Manila, triggered by the southwest monsoon in the first week of that month. In January 2012, 1,332 cases were seen, the second highest number of cases reported for that year. This was due to the flooding in the Northern Mindanao Region brought about by typhoon Sendong in December of the previous year. ${ }^{10}$

The National Capital Region (NCR) is constantly ranked among the top three regions with the most leptospirosis cases in the Philippines, with the City of Manila consistently having the most cases in the NCR. ${ }^{8}$

Various researchers have sought to estimate the level of leptospirosis-related knowledge and practices among different populations. ${ }^{11,12,13,14}$ In a study among abattoir workers in northwestern Nigeria, only four out of the 73 
participants are aware of the existence of leptospirosis. ${ }^{11}$ In a study among town service workers in Malaysia, only $7 \%$ of the respondents have good knowledge on leptospirosis. ${ }^{12} \mathrm{~A}$ 2013 study among urban slum residents in Brazil found that more than two-thirds of the participants are able to correctly identify the modes of disease transmission and exposure reduction. ${ }^{13}$ In a Metro Manila study, the majority of the participants, mostly mothers, have good leptospirosisrelated knowledge. ${ }^{14}$ Only one study that aimed to investigate the association of these two variables was obtained. This paper found that low knowledge is associated with unsatisfactory practice $(\mathrm{p}=0.003) .{ }^{15}$

In a 2000 study conducted on non-motorized modes of transportation, most pedicab drivers in Manila are males as young as 15 who lived below the poverty threshold, making 1,000 to 3,000 pesos per month on average supporting a household with 3 to 5 people. ${ }^{16}$ Thus, they must work seven days a week from six in the morning until very late in the evening to be able to make ends meet, including working in extremely stormy weather despite heavy flooding as stranded commuters are a good source of income particularly for those who only need to traverse short distances but are unable to do so due to high water levels.

In the first three quarters of $2013,86 \%$ of the 1,174 leptospirosis cases in the country were male. ${ }^{9}$ Although the literature has yet to include pedicab drivers in the high-risk group, the researchers believe that due to their predominantly male population and the nature of their occupation that exposes them to floodwaters, they can be considered a part of this group.

This study aimed to examine the association of leptospirosis-related knowledge and practices. Specifically, it aimed to 1) determine the level of knowledge on leptospirosis as well as the preventive and health-seeking practices of pedicab drivers in some areas in Manila City, and 2) determine if an association exists between their leptospirosis-related knowledge and practices.

It is the hope of the researchers that the result of this study will help policy makers and health educators in their task of formulating health policies and programs to decrease the incidence of leptospirosis particularly among the vulnerable population of pedicab drivers.

\section{Materials and Methods}

\section{Study Design and Study Areas}

The study employed an analytic cross-sectional study design. Four zones were chosen as the study areas: 1) University of Santo Tomas (UST) area; 2) Bacood area; 3) Polytechnic University of the Philippines (PUP) Sta. Mesa area; and 4) De La Salle University/De La Salle-College of Saint Benilde (DLSU/CSB) area. These areas were chosen because they are known to be very prone to flooding and the pedicab drivers in these areas have organizations which can be tapped to facilitate communications between the researchers and the pedicab drivers.

\section{Study participants}

Male pedicab drivers aged 18 to 59 years were included in the study. The pedicab drivers must have been following the same route for at least six months. It was assumed that after six months following the same route, the pedicab drivers would have established routine practices.

\section{Sampling Design}

The initial plan was to use stratified random sampling with proportional allocation to select pedicab drivers. The pedicab drivers were stratified according to their routes/areas. Lists of pedicab drivers that were obtained from the Pedicab Operators and Drivers Organizations (PODA) in the four areas were utilized as the sampling frame. However, this method was not feasible because most of the randomly selected drivers were not in the line of drivers waiting for passengers when the interviewers went to the designated terminals/waiting areas. The researchers then resorted to simply requesting the participation of pedicab drivers satisfying the inclusion criteria who were lined up and waiting for passengers at the time of data collection. A total of 174 male pedicab drivers who satisfied the inclusion criteria were included in the study.

\section{Method of Data Collection and Data Collection Tool}

Face-to-face interviews were done using a prepared interview schedule. Socio-demographic and economic characteristics of the participants were gathered. Moreover, the interview schedule contains twelve questions on the knowledge of the participants on the transmission and prevention of leptospirosis. Five questions were used to determine the knowledge of the respondents on the transmission of leptospirosis. These consisted of items on transmission through rat bite; entry of infected rat urine through nose, eyes, and mouth; and through abrasions in the skin. Seven questions were used to determine the knowledge of the respondents on leptospirosis infection prevention. "Avoidance of walking barefoot", "swimming in water that may be contaminated with rat urine" and "wearing of boots during floods" were some of the items included.

Eight questions pertaining to practices such as not driving their pedicab when there is a flood, wearing boots when driving in flood, and washing their feet after wading in flood, and health-seeking behavior such as going to a medical practitioner when experiencing any symptoms after wading in flood were included. The questions were answerable by yes or no.

\section{Variables of the Study}

The independent variable knowledge was defined as the respondents' awareness of the cause and prevention of leptospirosis. A participant was classified as having good 
knowledge if he was able to correctly answer at least nine (75\%) of the twelve knowledge questions described in the previous section. Otherwise, he was classified as having poor knowledge on leptospirosis.

The dependent variable practice was defined as the methods that participants used to protect themselves from acquiring leptospirosis during floods, as well as their healthseeking behavior. A participant was classified as having satisfactory practice if he reported doing at least six (75\%) of the eight identified preventive and health-seeking practices. Otherwise, he was classified as having unsatisfactory practice.

The other variables that were collected because of their potential to confound or to vary the effect of knowledge on practices were age, educational attainment, years as a pedicab driver, average daily income, ownership of the driven pedicab, and acquaintance with another person who had been diagnosed with leptospirosis.

\section{Data Analysis}

The means and standard deviations were computed for quantitative data while frequencies and percentages were obtained for qualitative variables.

For the model building, crude analysis of each variable was initially done to determine the probable confounders at 0.25 level. This cut-off value was chosen to avoid the exclusion of variables which may be weakly associated due to the confounding of other variables.

The next step was the stratified analysis in which the potential effect measure modifiers (EMM) were identified. EMMs are variables across which the effect of the exposure variable on the outcome variable differs. Woolf's test of heterogeneity was utilized to examine probable effect measure modification at 0.1 level of significance.

Effect measure modification was subsequently assessed using the model that includes leptospirosis-related knowledge as the independent variable, the probable EMM identified in the previous step, and their interaction. An interaction term was considered statistically significant if the resulting $\mathrm{p}$-value is less than or equal to 0.1 .

Finally, confounders were assessed using backward elimination method. Confounding by a variable was determined by comparing the odds ratio (OR) derived from the reduced model to that of the full model. The variable was considered a confounder and was retained in the model if the relative change in the OR was at least $10 \%$. The process ended when insignificant confounders could no longer be deleted.

The final model was composed of the outcome, exposure variable, the significant confounders and EMM. Stratum-specific ORs were obtained should there be a significant EMM. The ORs, the $90 \%$ confidence interval (CI) estimates, and the resulting $\mathrm{p}$-values were presented. The
90\% CI was utilized since it more closely approximates exact intervals. ${ }^{17}$

\section{Ethics Statement}

The University of the Philippines College of Public Health Ethics Review Committee reviewed and approved the research protocol. An informed consent was obtained from each participant prior to conducting the interview. The anonymity of the respondents and the confidentiality of data were protected.

\section{Results}

Sociodemographic Profile and other relevant characteristics of the participants

The mean age of the 174 pedicab drivers was 37 years. Their distribution by age decreased as age increased. The majority (56\%) were either married or in a live-in relationship. Around 6 out of 10 participants reached secondary level of education. On average, the respondents had been pedicab drivers for 9.3 years. Almost $45 \%$ had been driving pedicabs for at most 5 years while $10 \%$ had been pedicab drivers for over 20 years (Table 1).

Table 1. Sociodemographic Profile of Pedicab Drivers, Manila, November 2013 ( $\mathrm{n}=174$ )

\begin{tabular}{lc}
\hline Sociodemographic Characteristic & No. of Pedicab Drivers (\%) \\
\hline Age group & $55(31.6)$ \\
$18-29$ & $44(25.3)$ \\
$30-39$ & $45(25.8)$ \\
$40-49$ & $30(17.2)$ \\
$50-59$ & $37.2 \pm 11.9$ \\
Mean \pm sd & 37 \\
Median & $18-59$ \\
Range & \\
Civil Status & $58(33.3)$ \\
Single & $98(56.3)$ \\
Married/Live-in & $18(10.3)$ \\
Separated/widower & \\
Educational Attainment & $47(27.0)$ \\
None / Elementary level & $110(63.2)$ \\
Secondary level & $17(9.8)$ \\
College level & \\
Years as a Pedicab Driver & $4(2.3)$ \\
less than 1 & $73(42.0)$ \\
$1-5$ & $41(23.6)$ \\
$6-10$ & $23(13.2)$ \\
$11-15$ & $16(9.2)$ \\
$16-20$ & $17(9.8)$ \\
More than 20 & $9.3 \pm 7.9$ \\
Mean \pm sd & 6.5 \\
Median & $0.5-38$ \\
Range &
\end{tabular}

More than half of the respondents reported not owning the pedicabs they drove. Their average daily income was Php 300.50 (Table 2). 
Table 2. Economic Profile of Pedicab Drivers, Manila, November 2013 ( $n=174)$

\begin{tabular}{lc}
\hline \multicolumn{1}{c}{ Economic Characteristic } & No. of Pedicab Drivers (\%) \\
\hline Daily Income (in Php) & $1(0.6)$ \\
Less than 100 & $16(9.2)$ \\
$100-199$ & $51(29.3)$ \\
$200-299$ & $69(39.7)$ \\
$300-399$ & $28(16.1)$ \\
$400-499$ & $8(4.6)$ \\
At least 500 & $1(0.6)$ \\
No information & $300.5 \pm 97.3$ \\
Mean \pm sd & 300 \\
Median & $85-650$ \\
Range & \\
Pedicab Ownership & $75(43.1)$ \\
Owner & $99(56.9)$ \\
Not an owner &
\end{tabular}

Ninety-six pedicab drivers (55\%) said they knew someone who had been diagnosed with leptospirosis.

\section{Leptospirosis-related Knowledge}

Among the 174 pedicab drivers, 15\% said that they have not heard of the disease. More than $80 \%$ correctly stated that leptospirosis comes from the urine of infected rats and that a person with a skin abrasion that comes in contact with rat urine infected with leptospirosis can get the disease. However, only $37 \%$ and $46 \%$ reported that they knew that leptospirosis is not caused by rat bites and that entry of the urine of infected rats through the mucus membranes (i.e. nose, eyes, and mouth) also causes the disease, respectively (Table 3).

On the respondents' knowledge on prevention of leptospirosis, $76 \%$ said that the disease can be prevented by wearing boots while driving in flood, almost 6 out of 10 correctly identified the avoidance of swimming in contaminated waters as a preventive practice, and $66 \% \mathrm{knew}$ that the disease can be prevented by avoiding walking barefoot. However, only $21 \%$ and $40 \%$ agreed that covering one's mouth and avoidance of streams and rivers after a flood are preventive measures against leptospirosis, respectively (Table 3).

Forty-nine percent of the pedicab drivers (90\% CI: $42.9 \%, 55.9 \%$ ) were classified as having good knowledge on the cause and prevention of leptospirosis.

\section{Leptospirosis-related Practices of Pedicab Drivers}

Approximately two out of 10 pedicab drivers reportedly practice three preventive measures, namely: a) not wading in floodwaters $(14 \%)$; b) not driving a pedicab when there is a flood (16\%); and c) wearing boots when wading or driving a pedicab when there is a flood (19\%).

The reported health-seeking behavior and other preventive practices of the respondents, however, were found to be good. More than $90 \%$ said that they would wash their feet after wading in flood or that they would drink lots of water when not feeling well. Seventy-two percent reported that they would seek the help of a medical professional when experiencing any of the symptoms of leptospirosis (Figure 1).

Table 3. Distribution of Pedicab Drivers according to Correct Responses on the Causes, Signs, and Symptoms of Leptospirosis, Manila, November $2013(\mathrm{n}=174)$

\begin{tabular}{|c|c|}
\hline Indicators of Knowledge on Leptospirosis & $\begin{array}{l}\text { No. of Pedicab } \\
\text { Drivers (\%) }\end{array}$ \\
\hline \multicolumn{2}{|l|}{ Causes } \\
\hline Leptospirosis comes from urine of infected rats. & $142(81.6)$ \\
\hline $\begin{array}{l}\text { If the urine of rats infected with leptospirosis comes in } \\
\text { contact with the abrasions in the skin, the person } \\
\text { will get infected. }\end{array}$ & $142(81.6)$ \\
\hline $\begin{array}{l}\text { Entry of the urine of infected rats in the nose, eyes, and } \\
\text { mouth can get a person infected with } \\
\text { leptospirosis. }\end{array}$ & $80(46.0)$ \\
\hline $\begin{array}{l}\text { The microorganism that causes leptospirosis does not } \\
\text { enter the body through closed wounds (like } \\
\text { bruises) in the skin. }\end{array}$ & $72(41.3)$ \\
\hline Rat bite does not cause the disease called leptospirosis. & $65(37.4)$ \\
\hline \multicolumn{2}{|l|}{ Prevention } \\
\hline $\begin{array}{l}\text { Wearing boots when there is flood can prevent } \\
\text { leptospirosis. }\end{array}$ & $132(75.9)$ \\
\hline $\begin{array}{l}\text { Avoidance of walking barefooted can prevent } \\
\text { leptospirosis. }\end{array}$ & $115(66.1)$ \\
\hline $\begin{array}{l}\text { Avoidance of drinking stream water is a preventive } \\
\text { measure against leptospirosis. }\end{array}$ & $104(59.8)$ \\
\hline $\begin{array}{l}\text { Avoidance of swimming in water contaminated with } \\
\text { urine of infected rat is a preventive measure } \\
\text { against leptospirosis. }\end{array}$ & $101(58.1)$ \\
\hline Leptospirosis can be prevented by not going to canals. & $91(52.3)$ \\
\hline $\begin{array}{l}\text { Leptospirosis can be prevented by not going to the } \\
\text { river/stream right after floods. }\end{array}$ & $70(40.2)$ \\
\hline $\begin{array}{l}\text { Leptospirosis can be prevented by covering the mouth } \\
\text { during rainy season. }\end{array}$ & $36(20.7)$ \\
\hline
\end{tabular}

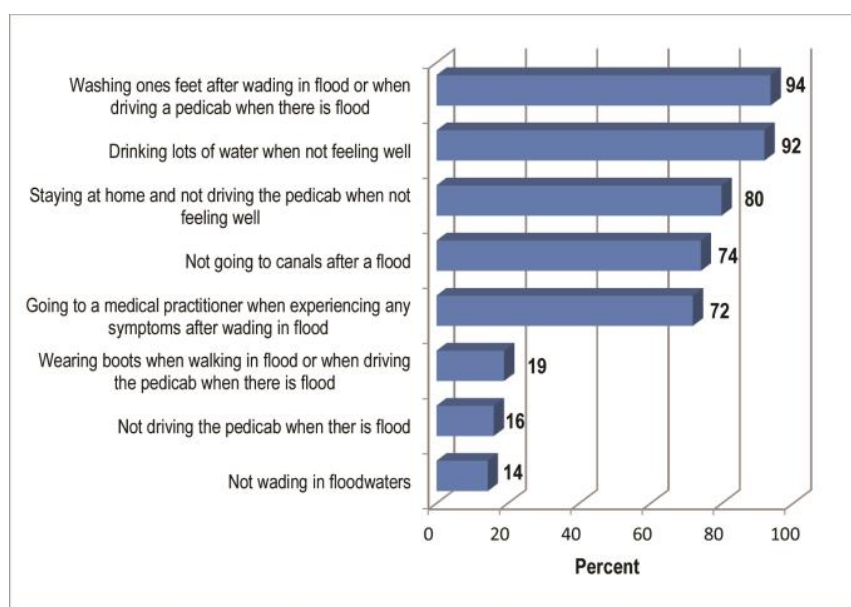

Figure 1. Proportion of Pedicab Drivers Who Reported Having Correct Preventive Practices and Good HealthSeeking Behavior, Manila, November 2014 ( $n=174)$ 
Table 4. Crude Associations of Socioeconomic and Leptospirosis-related Factors with Practice of Pedicab Drivers, Manila, November $2013(n=174)$

\begin{tabular}{|c|c|c|c|c|}
\hline Factor & $\begin{array}{l}\text { No. of Pedicab Drivers with } \\
\text { Poor Practice / Total }\end{array}$ & $\begin{array}{l}\text { \% with Poor } \\
\text { Practice }\end{array}$ & $\begin{array}{c}\text { Unadjusted OR } \\
(90 \% \mathrm{CI})\end{array}$ & p-value \\
\hline \multicolumn{5}{|l|}{ Age } \\
\hline $18-29$ & $44 / 55$ & 76 & 1.0 & - \\
\hline $30-39$ & $36 / 44$ & 82 & $1.4(0.6,3.2)$ & 0.510 \\
\hline $40-49$ & $38 / 45$ & 84 & $1.7(0.7,3.9)$ & 0.318 \\
\hline $50-60$ & $22 / 30$ & 73 & $0.9(0.4,2.0)$ & 0.757 \\
\hline \multicolumn{5}{|l|}{ Educ } \\
\hline At most Elementary graduate & $40 / 47$ & 85 & $1.7(0.8,3.6)$ & 0.255 \\
\hline At least High School level & $98 / 127$ & 77 & 1.0 & - \\
\hline \multicolumn{5}{|l|}{ Years as a pedicab drivers } \\
\hline Less than 8 years & $68 / 93$ & 73 & 1.0 & - \\
\hline At least 8 years & $70 / 81$ & 86 & $2.3(1.2,4.5)$ & 0.034 \\
\hline \multicolumn{5}{|l|}{ Ownership of pedicab } \\
\hline Owner & $55 / 75$ & 73 & 1.0 & - \\
\hline Not an owner & $83 / 99$ & 84 & $1.9(1.0,3.5)$ & 0.093 \\
\hline \multicolumn{5}{|l|}{ Daily income (in pesos) } \\
\hline Less than 300 & $53 / 69$ & 77 & 1.0 & - \\
\hline At least 300 & $85 / 105$ & 81 & $1.3(0.7,2.4)$ & 0.510 \\
\hline \multicolumn{5}{|c|}{ Knew somebody who have had leptospirosis } \\
\hline No & $64 / 78$ & 82 & $1.4(0.7,2.5)$ & 0.422 \\
\hline Yes & $74 / 96$ & 77 & 1.0 & \\
\hline \multicolumn{5}{|c|}{ Knowledge on cause and prevention of leptospirosis } \\
\hline Good & $63 / 86$ & 73 & 1.0 & - \\
\hline Poor & $75 / 88$ & 85 & $2.1(1.1,4.0)$ & 0.054 \\
\hline
\end{tabular}

Of the 174 participants, only $20.7 \%$ (90\%CI: $15.8 \%$, $26.4 \%$ ) were shown to have satisfactory preventive and health-seeking practices.

Association of Leptospirosis-related Knowledge and Practices of Pedicab Drivers

Table 4 presents the crude associations of the practices of pedicab drivers with knowledge, socioeconomic, and other leptospirosis-related factors. The number of years as a pedicab driver and pedicab ownership were found to be potential confounders of the association between having poor leptospirosis-related knowledge and unsatisfactory practices.

Using the algorithm described in the methodology, the variable that was found to have a significant confounding effect on the association between having poor leptospirosisrelated knowledge and unsatisfactory practices was ownership of the pedicab used. Moreover, educational attainment was found to be a significant effect measure modifier since the association of knowledge and practices varied with the level of education.

Among the pedicab drivers who reached at least the secondary level of education, knowledge was not significantly associated with practices $(\mathrm{p}=0.533)$ (Table 5). However, a significant association was found among less educated pedicab drivers. Among the drivers who had at most elementary education, the odds of having unsatisfactory practices among those with poor knowledge on the causes and prevention of leptospirosis were thirteen times higher than that of pedicab drivers with good knowledge $(\mathrm{OR}=12.9$, $\mathrm{p}=0.024)$.

Table 5. Stratum-specific Odds Ratio Estimates for Association of Poor Knowledge with Unsatisfactory Practices by Level of Education of Pedicab Drivers, Manila, November $2013(n=174)$

\begin{tabular}{cccc}
\hline Effect Modifier & $\begin{array}{c}\text { Odds } \\
\text { Ratio }\end{array}$ & $\begin{array}{c}\mathbf{9 0 \%} \\
\text { Confidence } \\
\text { Interval }\end{array}$ & p-value \\
\hline $\begin{array}{c}\text { Education } \\
\text { At most elementary graduate }\end{array}$ & 12.93 & $1.39,120.29$ & 0.024 \\
At least secondary level & 1.31 & $0.64,2.66$ & 0.533 \\
\hline
\end{tabular}

\section{Discussion}

This study classified almost $50 \%$ of the participating pedicab drivers as having a good level of knowledge on the cause and prevention of leptospirosis. In comparison, only $6 \%$ of 73 abattoir workers in a northwestern Nigeria study ${ }^{11}$ and $13 \%$ of 296 service town workers in Malaysia ${ }^{12}$ are aware of the existence of leptospirosis. The authors of the former study suggested that their respondents' very low awareness of the disease is due to the lack of an equivalent translation in the local language. The contrast in the results may be attributed to the fact that many Filipinos are able to understand English. In addition, among the participating pedicab drivers, leptospirosis was colloquially called "leptos". Converting the term into a much easier to pronounce version allowed for the disease to be talked about among friends and fellow pedicab drivers. 
The reported knowledge of the interviewed mothers in a 2013 Metro Manila study ${ }^{14}$ and the pedicab drivers of this study were similar except for some key questions. Eightyfour percent of the mothers correctly stated that leptospirosis is not caused by rat bites whereas only $36 \%$ of the pedicab drivers responded correctly. On prevention, not going to streams and rivers after floods and not going to canals were correctly identified as preventive measures by $78 \%$ and $91 \%$ of the mothers, respectively, compared to only $43 \%$ and $53 \%$ of the pedicab drivers giving correct responses in this study. These discrepancies may be due to the diference in the sampled populations and their access to information. Mothers were the participants of the 2013 Metro Manila study. Since these participants were mostly housewives who stayed at home, they had more opportunities to watch television or listen to the radio, thus gaining more access to leptospirosis-related information through these media. Moreover, since the mothers generally take care of other members of the family, particularly the children, they may have more interest in acquiring knowledge about diseases and how to protect their families against them.

This study found that only $36(21 \%)$ of the respondents had satisfactory practices. This finding is similar to those of previous studies among town service workers in Malaysia, ${ }^{12}$ urban slum residents in Brazil, 13 and mothers in Metro Manila ${ }^{14}$ that also reported low proportions of respondents having adequate practices for the prevention of leptospirosis. Specifically, only 36\% of 296 respondents in the Malaysian study are classified as having satisfactory practices..$^{12}$ It is noteworthy that the three studies mentioned and this paper found that at most $40 \%$ of the respondents reported using boots during floods. In particular, this study found that only $19 \%$ percent of those surveyed used boots when wading or working in floodwaters.

On the other hand, a higher proportion (62\%) of abattoir workers in Nigeria use boots. ${ }^{11}$ The difference may be due to the work environtment of the abattoir workers where rules or reminders of proper work attire can be placed. Whether or not these rules are strictly enforced, constant reminders through signs may have had an effect. Thus, the majority of Nigerian abattoir workers in the study wear boots while working despite their very low awareness of leptospirosis (6\%).

It was also found that $86 \%$ and $84 \%$ of the pedicab drivers reported wading in floodwaters and driving their pedicabs through floods, respectively. This is because it is very profitable to seek customers during times of flood when they would charge the passengers at least five times the usual amount.

In general, a greater proportion of respondents reported staying home when they felt sick (80\%), having high fluid intake when sick $(92 \%)$, and washing their feet after wading in floodwaters $(94 \%)$, suggesting that many of the pedicab drivers were aware of and practiced general methods of disease prevention.

Ownership of the driven pedicab was found to statistically confound the association between leptospirosisrelated knowledge and practices. Pedicab drivers who did not own the pedicab that they drove needed to pay the pedicab owner a minimum of Php100 (\$2.25) as boundary fee on a daily basis. In flooded areas, pedicab drivers would charge as much as Php100 per ride, whereas the average fee for rides in flood-free areas of the same distance would only cost around Php20 to Php50 (\$0.45 - \$1.12). The investigators conclude that pedicab drivers who needed to pay boundary fees were more likely to have poor preventive practices against leptospirosis since flood-prone areas would allow them to charge more for the same distance. Moreover, pedicab owner-drivers may have greater independence, able to decide whether or not to continue to pedal through floods or cease for safety reasons. Furthermore, despite the lack of literature, it could be argued that pedicab owner-drivers tend to have higher level of knowledge than non-owners. It could be assumed that pedicab owner-drivers have more access to sources of information on leptospirosis, having more time for recreation and self-education than non-owners who must work more to earn a profit on top of the boundary fees they need to pay.

When pedicab ownership was excluded in the model, the odds of having unsatisfactory practices among those with poor knowledge were 14 times as high as those with good knowledge. Thus, not controlling for the confounding effect of pedicab ownership pulled the estimate away from the null.

Education was a significant effect measure modifier. The association was not significant among pedicab drivers with at least secondary education. However, among those with low educational attainment, a statistical association was found. The odds of having unsatisfactory practices among those with poor knowledge in this group were 13 times as high as those with good knowledge. This proposes that the interaction of poor knowledge and low educational level increases the odds of having unsatisfactory preventive and health-seeking practices.

The association, however, may have been magnified by some bias. Firstly, leptospirosis-related practices were reported by the participants but not actually observed by the researchers. Pedicab drivers could easily say that they perform leptospirosis-preventive practices without actually performing them, leading to information bias. Moreover, social desirability bias was highly likely. Because the knowledge of the pedicab drivers was relatively good, they could have reported performing methods of prevention when they in fact did not. Because of these potential biases, there may be an overestimation of the odds ratio.

Nevertheless, the results of this study suggest that increasing the knowledge on the cause and prevention of 
leptospirosis among pedicab drivers especially those with low levels of education is necessary to improve their preventive and health-seeking practices.

The Diffusion of Innovations model of learning states that the process of diffusion of innovations such as through health promotion programs has several stages: dissemination, adoption, implementation, maintenance, sustainability, and institutionalization. In the second stage, the decision to adopt an innovation or behavior is dependent on a number of factors. One of these is knowledge: knowledge that the innovation exists, knowledge on how the innovation works, and knowledge on how to use the innovation. ${ }^{18}$ Thus, disseminating information on leptospirosis and the ways to prevent it is important. Mass media such as television and tabloids are useful ways to circulate information on leptospirosis since a good proportion of participants cited these as their sources of particulars on the disease. Information on prevention of leptospirosis may be placed in tabloids as most of the pedicab drivers read these while waiting for passengers at terminals and waiting areas. Moreover, health workers may collaborate with the PODAs in different areas to organize health information seminars for pedicab drivers.

\section{Conclusions}

A low level of education combined with poor leptospirosis-related knowledge was found to have a magnified effect on practices. Increasing the knowledge on the cause and prevention of leptospirosis of pedicab drivers may be necessary to improve their preventive and healthseeking practices especially among those with low level of education. Information dissemination on leptospirosis using televisions and newspapers or tabloids should be further intensified. City health workers and the organizations of pedicab drivers can also collaborate to organize health information seminars specifically targeting pedicab drivers.

\section{References}

1. Dugale D. Leptospirosis [Online]. [cited 2013 October]. Available from http://www.nlm.nih.gov/medlineplus/ency/article/001376.htm.

2. Few R. Flood hazards and health: Responding to present and future risks. CRC Press; 2013.

3. Pappas G, Papadimitrou P, Siozopolou V, Christou L, Akritidis N. The Globalization of leptospirosis: Worldwide incidence trends. Int J Infect Dis. 2008; 12(4):351-7.

4. Lau CL, Smythe LD, Craig SB, Weinstein P. Climate change, flooding, urbanization and leptospirosis: fuelling the fire? Trans R SocTrop Med Hyg. 2010; 104(10):631-8.

5. Zavitsanou A, Babatsikou F. Leptospirosis: Epidemiology and preventive measures. Health Sci J. 2008; 2(2):75-82.

6. Wasinski B, Dutkiewicz J. Leptospirosis - current risk factors connected with human activity and the environment. Ann Agric Environ Med. 2013; 20(2):239-44.

7. Sehgal SC. Epidemiological patterns of leptospirosis. Indian J Med Microbiol. 2006; 24(4):310-1.
8. National Epidemiology Center, Department of Health. Disease surveillance report morbidity week 33 [Online]. [cited 2013]. Available from http://www.doh.gov.ph/sites/default/files/leptoup33.pdf

9. National Epidemiology Center, Department of Health. Disease surveillance report morbidity week 33 [Online]. [cited 2013]. Avaialble from http://www.doh.gov.ph/sites/default/files/leptoup36.pdf

10. Department of Health. The Surge of Leptospirosis [Online]. [cited 2013 November]. Available from http://doh.gov.ph/content/surgeleptospirosis.html.

11. Ngbede EO, Raji MA, Kwanashie CN, et al. Risk practices and awareness of leptospirosis in an abattoir in Northwestern Nigeria. Sci J Vet Adv. 2012; 1(2):65-9

12. Mohd Rahim S, Aziah BD, Mohd Nazri S, et al. Town service workers' knowledge, attitude and practice towards leptospirosis. Brunei Darussalam Journal of Health. 2012; 5:1-12.

13. Navegantes de Araujo W, Finkmoore B, Ribeiro GS, et al. Knowledge, attitudes and practices related to leptospirosis among urban slum residents in Brazil. Am J Trop Med Hyg. 2013; 88(2):359-63.

14. Guevarra JP, Borja MP, Gloriani NG, Yoshida S, Napulan R. Knowledge, attitudes and practices of the community concerning the prevention and control of leptospirosis in the National Capital Region, Philippines. Metro Manila. 2013. Unpublished.

15. Brown AP. Knowledge, attitudes, perceptions and practices of residents of Port Maria, St. Mary, with respect to leptospirosis and rodent control [MS Thesis]. University of the West Indies; 2006.

16. Guillen MD. A study of non-motorized public transport in urban and urbanizing areas: the case of pedicab operations in the City of Manila and in the Municipality of Los Banos, Laguna [MS Thesis]. University of the Philippines Diliman; 2000.

17. Rothman KJ, Greenland S. Modern epidemiology, $2^{\text {nd }}$ ed. Philadelphia: Lippincott Williams and Wilkins, 1998.

18. Glanz K, Rimer BK, Viswanath K. Health behavior and health education: theory, research and practice, $4^{\text {th }}$ ed. California: John Wiley \& Sons, Inc., 2008 